\title{
Satisfação e fidelização de clientes do setor bancário brasileiro
}

\section{Satisfaction and customer loyalty in the Brazilian banking sector}

\author{
Daniel Barbosa Cabral Mestre em Administração. Universidade Federal Rural da Amazônia (UFRA) - Brasil. \\ danicabral@msn.com \\ Nancy Maria Correa Torres Bacharel em Administração. Universidade Federal Rural da Amazônia (UFRA) - Brasil. \\ nancymaria.torres@gmail.com
}

\section{RESUMO}

Este artigo tem o objetivo de identificar os motivos que levam os clientes do setor bancário a tornarem-se satisfeitos e fidelizados a um banco. A pesquisa é quantitativa de natureza exploratória e descritiva. Para alcançar este resultado, foi realizada uma pesquisa bibliográfica sobre o tema em artigos nacionais e internacionais, em seguida, elaborado um questionário estruturado que foi aplicado com 474 clientes bancários no munícipio de Parauapebas, estado do Pará. Os dados foram analisados com técnicas estatísticas descritivas e análise fatorial. Os resultados demonstram que a reputação do banco, conquistada através de relacionamentos de confiança e atendimento assertivo, e a qualidade e confiabilidade dos serviços on-line são os principais fatores que favorecem a satisfação e fidelização dos clientes.

Palavras-chave: Satisfação do Cliente. Fidelização do Cliente. Qualidade do Atendimento. Tecnologia da Informação. Setor Bancário.

\section{ABSTRACT}

This article aims to identify the reasons that lead to customer satisfaction and customer loyalty in the banking sector. The research is quantitative of an exploratory and descriptive nature. To achieve this result, bibliographic research was carried out on the subject in national and international articles. Then, a structured questionnaire was elaborated and applied to 474 bank clients in the Parauapebas city, state of Para. Data were analyzed using statistical descriptive techniques and factorial analysis. The results demonstrate that the bank's reputation, achieved through reliable relationships and assertive service, and the quality and reliability of online services are the main factors that favor customer satisfaction and loyalty.

Keywords: Customer Satisfaction. Customer Loyalty. Customer Service. Information Technology. Banking. 


\section{INTRODUÇÃO}

A satisfação do cliente pode ser entendida como o cumprimento integral das expectativas em um relacionamento entre clientes e empresas. É uma atitude ou sentimento que resulta após os clientes utilizarem produtos ou serviços das empresas. As atividades de marketing estão diretamente ligadas à satisfação do cliente e, às vezes, estão associadas ao comportamento de compra dos consumidores (ALI; RAZA, 2017).

As instituições bancárias devem estar cientes de que a satisfação e fidelização dos clientes podem estar baseadas em fatores específicos de conveniência e qualidade de serviço, como por exemplo, acesso ao banco através de dispositivos eletrônicos conectados à internet, as taxas de juros competitivas, localização das agências, tarifas bancárias com menor custo, reputação e outros fatores.

O relacionamento banco-cliente de alta qualidade pode ajudar os bancos a atender os clientes de maneira mais satisfatória e os clientes têm maior probabilidade de confiar em um banco, o que acabará melhorando a sua reputação (HAMZAH; LEE; MOGHAVVEMI, 2017). Além disso, é importante que os bancos garantam que seus clientes acreditem na confiabilidade dos serviços bancários prestados de forma eletrônica e que vale a pena recomendá-los a amigos e familiares (VAN TONDER et al., 2018).

O setor bancário brasileiro está em rápido crescimento e opera em um ambiente de concorrência cada vez maior. As semelhanças entre os serviços oferecidos pelos bancos estão cada vez maiores e são necessários parâmetros de diferenciação para as empresas cresceram e se manterem no mercado (BEZERRA; MIRANDA; MOREIRA, 2016).

Nesse ambiente altamente competitivo, os bancos que esperam obter vantagem sobre seus concorrentes precisam melhorar continuamente a qualidade dos serviços que prestam aos seus clientes, levando em consideração suas expectativas no aprimoramento dos serviços (YLMAZ ; ARI; GÜRBÜZ, 2018). Quanto maior o nível de satisfação do cliente com o atendimento, não apenas com os produtos ou serviços contratados, maior a probabilidade de o cliente ser fiel à empresa que fornece esses serviços ou produtos (CHUMPITAZ CACERES; PAPAROIDAMIS; 2007).

Para Amegbe e Osakwe (2018), novas pesquisas devem ser feitas para explorar em detalhes a fidelização dos clientes no setor bancário, pois mesmo os clientes bancários que são muito fiéis aos seus prestadores de serviços podem mudar a sua base de fidelidade para outros prestadores de serviço ao longo do tempo e não necessariamente devido às baixas taxas de satisfação ou insatisfação com os serviços prestados. Diante deste cenário, esta pesquisa pretende responder à seguinte questão: Quais os motivos que levam os clientes do setor bancário a tornarem-se satisfeitos e fidelizados?

O objetivo deste trabalho é identificar os motivos que levam os clientes do setor bancário a tornaremse satisfeitos e fidelizados. Para alcançar este resultado, foram entrevistados 474 clientes bancários no munícipio de Parauapebas, estado do Pará. Os dados foram analisados com técnicas estatísticas descritivas e análise fatorial. Os resultados demonstram que a reputação do banco, conquistada através de relacionamentos de confiança e atendimento assertivo, e a qualidade e confiabilidade dos serviços on-line são os principais fatores que favorecem a satisfação e fidelização dos clientes.

\section{SATISFAÇÃO E FIDELIZAÇÃO DE CLIENTES BANCÁRIOS}

As intenções de comprar repetidamente o produto dependem muito da satisfação do cliente (TAYLOR; BAKER, 1994). Se um cliente estiver satisfeito com um serviço ou produto depois de usá-lo, então aumenta as chances de aumento na compra repetida desse serviço ou produto (EAST, 1997). Além disso, o cliente satisfeito compartilha sua experiência positiva com outros consumidores e se torna uma fonte de propaganda boca a boca, e por outro lado, quando o cliente está insatisfeito, isso resulta em propaganda boca a boca negativa e tem maior probabilidade de mudar a marca ou o produto consumido. (ALI; RAZA, 2017).

Melhorar a satisfação do cliente e, portanto, as taxas de retenção, pode vir de uma variedade de atividades disponíveis para a empresa. As evidências existentes sugerem que grandes ganhos na satisfação do cliente provavelmente virão de melhorias em qualidade dos serviços, recursos dos serviços e tratamento de reclamações de clientes (LEVESQUE; MCDOUGALL, 1996). 
Nesse contexto, é necessário que os bancos determinem o nível de satisfação dos seus serviços e resolvam quaisquer problemas e deficiências que identifiquem a respeito, no entanto, a resolução desses problemas depende da possibilidade de medi-los com precisão (CHUMPITAZ CACERES; PAPAROIDAMIS; 2007). A gestão das reclamações de clientes destaca-se como um dos mais eficazes e fáceis métodos de melhorar o padrão da qualidade propiciado aos clientes, aumentando, consequentemente, seu nível de satisfação (ZACHARIAS; FIGUEIREDO; ALMEIDA, 2008).

Em relação às reclamações dos clientes, os bancos devem tentar "acertar na primeira vez" (LEVESQUE; MCDOUGALL; 1996). A satisfação dos clientes de bancos de varejo depende, pelo menos em parte, da forma como o banco interage com o cliente e como administra esse relacionamento, seja por meio do atendimento dos gerentes, seja na forma como resolve os problemas dos clientes (ZACHARIAS; FIGUEIREDO; ALMEIDA, 2008).

Alguns autores afirmaram que pesquisas anteriores sobre lealdade focaram intensamente no paradigma da "satisfação que leva à lealdade" (WU, 2011; BAUMANN, ELLIOTT; HAMIN, 2011). Os clientes fidelizados são muito importantes para a sobrevivência de qualquer negócio devido à relação com a participação de mercado e lucratividade da empresa.

Em geral, o aumento da fidelidade leva a custos mais baixos de atendimento aos clientes da empresa, redução de despesas de marketing, aumento dos negócios da base de clientes existente e maiores lucros (LEVESQUE; MCDOUGALL, 1996). Embora o conceito de lealdade ou fidelização do cliente seja um tópico importante para os profissionais de marketing em serviços financeiros, atualmente há pouca concordância sobre os principais preditores de lealdade e suas inter-relações (BAUMANN, ELLIOTT; HAMIN, 2011).

O setor bancário é um exemplo clássico de atividade onde satisfação do cliente e recompra não são positivamente relacionados, pois, a satisfação do cliente não é necessária para garantir a fidelização, traduzida na forma de compra repetida ou na continuidade dos negócios (ZACHARIAS; FIGUEIREDO; ALMEIDA, 2008).

Ao aumentar a fidelização dos clientes, o banco de varejo (1) reduz seus custos de serviço, ou seja, as contas não precisam ser abertas ou fechadas e as classificações de crédito não precisam ser estabelecidas; (2) obtém conhecimento dos assuntos financeiros e das necessidades de seus clientes, permitindo assim uma segmentação eficaz e eficiente; e (3) amplia a oportunidade de venda cruzada de produtos e serviços existentes e novos (LEVESQUE; MCDOUGALL, 1996).

\section{QUALIDADE DO ATENDIMENTO NO SETOR BANCÁRIO}

O desempenho e a qualidade do serviço e produto podem ser antecedentes da satisfação no relacionamento, o que, por sua vez, afeta a confiança, o comprometimento e a lealdade aos negócios (CHUMPITAZ CACERES; PAPAROIDAMIS, 2007). Quando uma empresa executa um serviço negligentemente, quando comete erros evitáveis, e quando falha em cumprir as promessas feitas para atrair clientes, isso abala a confiança dos clientes em suas capacidades e prejudica suas chances de ganhar uma reputação de excelência em serviços (CHOUDHURY, 2013).

Hamzah, Lee e Moghavvemi (2017) indicam quatro dimensões-chave para a qualidade de atendimento dos bancos: (1) tangibilidade; (2) empatia; (3) confiabilidade e segurança; e (4) serviços bancários pela internet. Todas as dimensões relacionadas de forma significativa e positiva com a qualidade geral percebido pelos clientes do banco. Os resultados apresentados por Hamzah, Lee e Moghavvemi (2017) são indicativos do positivo efeito sobre a satisfação do cliente, sua confiança no banco e, finalmente, a reputação de um banco.

Para Cintamür e Yüksel (2018), cinco importantes variáveis fornecem apoio à importância da reputação corporativa nas decisões estratégicas de marketing do setor bancário e são elas: (1) Satisfação do consumidor, que verifica o quanto o cliente está satisfeito com os serviços prestados pelo banco; (2) Avaliação boca a boca positiva do banco, que identifica a como pessoas próximas ao cliente percebem o banco; (3) Intenção de comprar e usar serviços oferecidos pelo banco; (4) Intenção de comutação, que avalia o quanto o cliente está disposto a trocar de banco; e (5) Comprometimento do banco em atender as demandas dos clientes. 
Além disso, um relacionamento banco-cliente de alta qualidade pode ajudar o banco a atender os clientes de maneira mais satisfatória; e os clientes têm maior probabilidade de confiar em um banco, o que acabará melhorando a reputação de um banco (HAMZAH; LEE; MOGHAVVEMI, 2017).

Em estudo feito no setor bancário indiano, Choudhury (2013) apresenta quatro dimensões de qualidade de serviço percebida pelos clientes: (1) comportamento; (2) confiabilidade; (3) tangibilidade; e (4) conveniência. Embora estes resultados tenham sido obtidos no setor bancário da Índia, percebe-se semelhanças entre os estudos de Cintamür e Yüksel (2018) feitos na Turquia e os estudos de Hamzah, Lee e Moghavvemi (2017). Estes estudos contribuem para novos trabalhos serem desenvolvidos em outros países, como o Brasil.

\section{USO DA TECNOLOGIA NO SETOR BANCÁRIO BRASILEIRO}

Segundo a Pesquisa Nacional por Amostra de Domicílios realizada no ano de 2016 pelo Instituto Brasileiro de Geografia e Estatística - IBGE, no Brasil há aproximadamente 116 milhões de pessoas conectadas à internet, o equivalente a $64,7 \%$ da população com idade acima de 10 anos. O celular foi o principal dispositivo de acesso à internet no Brasil e utilizado por $94,6 \%$ dos internautas e $77,1 \%$ dos brasileiros possuíam algum celular (IBGE, 2018).

Os bancos de varejo também precisam estar cientes dos desenvolvimentos tecnológicos mais recentes e oferecer serviços que estejam alinhados às necessidades e exigências de seus clientes (VAN TONDER et al., 2018). Diante de um novo perfil de cliente que demanda soluções tecnológicas customizadas e experiências personalizadas, o setor bancário brasileiro elaborou sua estratégia de uso de novas tecnologias conjugadas ao atendimento presencial e digital de qualidade.

Segundo o relatório anual de 2017 divulgado pela Federação Brasileira dos Bancos - FEBRABAN, o setor bancário é o segmento de negócios com maiores investimentos em tecnologia no Brasil, somando R\$ 118,7 bilhões no período de 2012 a 2017 (FEBRABAN, 2018). Esses investimentos em tecnologia visam promover comodidade para os clientes. O mobile banking e o internet banking representam mais da metade operações realizadas pelos clientes do setor bancário no Brasil, conforme o Gráfico 1 a seguir:

Gráfico 1 - Transações Bancárias por Canal de Atendimento

\begin{tabular}{|c|c|c|c|}
\hline \multicolumn{4}{|c|}{ Em bilhões de transações } \\
\hline 2014 & 2015 & 2016 & \multirow{3}{*}{ Call Centers } \\
\hline $\begin{array}{l}2 \% \\
5 \%\end{array}$ & $2 \%$ & $\frac{2 \%}{7 \%}$ & \\
\hline $10 \%$ & $8 \%$ & $9 \%$ & \\
\hline $15 \%$ & $14 \%$ & $15 \%$ & - Correspondentes Bancários \\
\hline $21 \%$ & $18 \%$ & $16 \%$ & Agências Bancárias \\
\hline $37 \%$ & $32 \%$ & $24 \%$ & Terminais de Autoatendimento \\
\hline $10 \%$ & $20 \%$ & & -Mobile Banking \\
\hline 48,8 bi & $55,7 \mathbf{b i}$ & 65,4 bi & \\
\hline
\end{tabular}

Fonte: FEBRABAN (2018).

A inovação tecnológica promovida pelo setor bancário brasileiro é reconhecida em todo o mundo, fruto do investimento sustentado e da busca pelo aperfeiçoamento do sistema (FEBRABAN, 2018 ). 
O investimento e as despesas em tecnologia realizados pelos bancos em 2017 totalizaram R\$ 19,5 bilhões - aumento de $5 \%$ em relação a 2016 . Os gastos com software cresceram $13 \%$ no período e totalizaram R\$ 9,8 bilhões. É o que constatou a pesquisa Tecnologia Bancária solicitada pela FEBRABAN e conduzida pela consultoria global Deloitte em 2017. O levantamento, que contou com a participação de 24 instituições bancárias, identificou que o setor bancário no Brasil demandou investimentos com expansão maior que a média do setor mundial, que foi 3,6\%.

Esses elevados investimentos em tecnologia podem ser explicados pelo perfil dos brasileiros, que estão cada vez mais conectados. Considerando a faixa etária, os indivíduos com idade entre 18 e 24 anos apresentavam a maior taxa de conexão, com 85\% deles conectados, e os brasileiros com mais de 60 anos apresentavam o menor índice, com 25\% deles conectados (IBGE, 2018).

Embora cerca de $64,7 \%$ da população brasileira tenha declarado acessar a internet, há 63,3 milhões de pessoas que se mantêm fora dela e representam indivíduos disseram não saber usar ferramentas on-line, com $80 \%$ da população desconectada, ou que acham o serviço caro, com 14,3\% da população desconectada (IBGE, 2018). Esse grupo de clientes desconectados também requer dos bancos uma preocupação em qualidade de atendimento presencial nas agências.

\section{PROCEDIMENTOS METODOLÓGICOS}

A pesquisa de abordagem quantitativa é classificada como uma investigação exploratória e descritiva. A investigação ocorreu entre os meses de junho a dezembro de 2018 com clientes do setor bancário da cidade de Parauapebas, no estado do Pará. Os critérios para os clientes participarem das pesquisas são: (1) o cliente deverá ter idade maior ou igual a dezoito anos; e (2) o cliente deverá possuir conta corrente em bancos com agências localizadas na cidade de Parauapebas-PA.

Foi utilizado um questionário estruturado, elaborado através da revisão de literatura e análise de trabalhos publicados internacionalmente sobre o tema. Os trabalhos de Levesque (1996), Choudhury (2013), Hamzah, Lee e Moghavvemi (2017), Cintamür e Yüksel (2018) e Ylmaz , Ari e Gürbüz (2018) serviram de base teórica para a elaboração do questionário.

O questionário possui duas seções. Na primeira seção, dezessete perguntas para descrever o perfil dos entrevistados. Contém perguntas sobre características, como idade, sexo, ocupação, banco de relacionamento principal, tempo de relacionamento com o banco, frequência na agência física, utilização de atendimentos online e se conhece o seu gerente da conta corrente.

Na segunda seção do questionário, dezesseis perguntas que representam as variáveis analisadas sobre satisfação, fidelização e qualidade no atendimento bancário. As questões utilizaram a escala intervalar do tipo Likert para mensurar a intensidade das respostas. A escala contou com sete opções de resposta, sendo 1 (um) para discordo totalmente até 7 (sete) para concordo totalmente.

O questionário passou por uma fase preliminar de análise com cinco professores do curso de administração de uma universidade federal localizada na cidade de Parauapebas-PA, que estavam na condição de especialistas sobre o tema. Em seguida, após aprovação dos especialistas, os questionários foram aplicados eletronicamente, através da plataforma Google Forms e presencialmente, através de formulários de papel.

Para obter as respostas de forma eletrônica, os questionários foram enviados por e-maile aplicativos de mensagens para o setor de recursos humanos de empresas privadas e públicas, para o setor pessoal de órgãos públicos, contatos de alunos e professores de uma universidade federal. Para obter as respostas presenciais, foram realizadas duas seções de coletas de dados com frequentadores de um shopping center da cidade. Participaram 388 entrevistados de forma eletrônica e 86 de forma presencial, totalizando 474 entrevistados.

A amostra classificada como probabilística aleatória simples, foi calculada com 95\% de margem de segurança e 4,5\% de erro máximo admitido. Para o cálculo da amostra, foi utilizada a Equação 1, conforme Castro et al (2006), em que: $\mathrm{n}=$ tamanho da amostra (476); $\mathrm{Z}=$ desvio-padrão relacionado ao índice de confiança $(1,96) ; \mathrm{e}=$ erro amostral admitido $(4,5)$. 


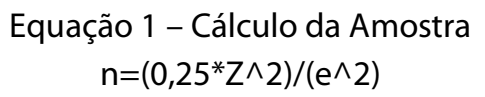

O tratamento dos dados coletados foi feito com técnicas de estatística descritiva e multivariada. Incialmente, separou-se os dados da primeira seção do questionário e analisou-se a frequência das respostas. Dessa forma, os dados foram classificados.

Para a segunda seção do questionário, utilizou-se a análise descritiva, calculando a média aritmética e desvio-padrão das respostas para uma das dezessete variáveis analisadas. Em seguida, foi feita a análise multivariada dos resultados. As técnicas multivariadas possuem como principal vantagem a habilidade em agrupar múltiplas variáveis na tentativa de compreender relações complexas não possíveis de serem observadas com a utilização dos métodos univariados (HAIR JUNIOR et al., 2009). Foi utilizada a técnica de análise fatorial exploratória, sendo possível reduzir o número de variáveis de dezessete para dez variáveis, encontrando os dois fatores resultantes da investigação.

Para alcançar o objetivo proposto neste trabalho, a seguinte hipótese de pesquisa foi formulada como: $\mathrm{H} \_\mathrm{O}=$ a satisfação com a qualidade do atendimento influencia na fidelização dos clientes bancários.

\section{DISCUSSÃO DOS RESULTADOS}

Os resultados são discutidos em duas subseções. A primeira descreve as características dos entrevistados e os resultados das questões sobre variáveis de atendimento. A segunda subseção apresenta a análise fatorial dos resultados.

\subsection{Análise descritiva dos resultados}

A pesquisa contou com a participação de 474 clientes bancários, sendo $57,6 \%$ mulheres e $42,4 \%$ homens. A média de idade dos participantes é de 26,4 anos. Sobre a ocupação dos participantes, os maiores grupos são de empregados de empresas privadas com $36,1 \%$ e servidores públicos com $24,1 \%$.

O Banco do Brasil teve mais entrevistados com 38,6\%, seguido por Bradesco com 19,6\%, Caixa Econômica Federal com 13,3\%, Itaú com 12\%, Santander com 8,9\% e outros com 7,6\%. O tempo de relacionamento médio entre os correntistas e os bancos é de 4,6 anos. A maioria dos entrevistados $(45,3 \%$ do total) frequentam as agências de forma presencial até três vezes por mês e $44,9 \%$ não frequentam as agências de forma presencial.

Sobre os serviços bancários on-line, como consultas de saldo da conta corrente, transferências, pagamentos e outros, $41,8 \%$ dos entrevistados utilizam mais de dez vezes por mês e apenas $13,3 \%$ não utilizam nenhum tipo de serviços bancários on-line. Esses resultados demonstram o crescimento dos canais de atendimento on-line e alterações significativas no comportamento dos consumidores.

Com o crescimento do atendimento por meios eletrônicos, conhecer o gerente pessoalmente passou a ser menos relevante para os consumidores. Apenas $36,7 \%$ dos entrevistados responderam que conhecem pessoalmente o gerente da sua conta corrente. É possível que os canais de atendimentos on-line provoquem a diminuição dos atendimentos presenciais pelos gerentes das contas correntes.

Entre os serviços mais utilizados pelos clientes, 75,7\% afirmam efetuar saques em caixas eletrônicos, $32,9 \%$ fazem depósitos por caixas eletrônicos, $35 \%$ utilizam os canais on-line para efetuar pagamentos de contas e $28,6 \%$ para fazer transferências bancárias. Sobre a visita presencial nas agências para solicitar algum serviço, apenas $23,6 \%$ dos clientes vão as agências para fazer consulta do saldo da conta corrente e $18,6 \%$ vão a agência resolver outros tipos de serviços não especificados.

Os clientes responderam sobre a contratação de serviços. Os serviços on-line permitem algumas contratações de produtos bancários pelos clientes. Para contratação de produtos em canais eletrônicos, 9,3\% dos clientes contratam empréstimos, 5,7\% realizam investimentos e 12,9\% efetuam outros serviços não especificados. 
Esses resultados revelam que as transações mais operacionais, como saques, depósitos e outras, o cliente está mais aderente em fazer através dos canais eletrônicos, entretanto, ainda há necessidade de o cliente comparecer às agências para realizar transações mais complexas. Isso pode ser explicado pelo atendimento humano permitir maior flexibilidade em entender as necessidades dos clientes e esclarecer suas dúvidas.

Os entrevistados responderam sobre as variáveis de atendimento do setor bancário. Os resultados são apresentados na Tabela 1 e estão em ordem decrescente a partir da média das repostas de cada variável.

A qualidade dos serviços on-linefoi a variável com maior avaliação dos entrevistados. A qualidade dos serviços é uma variável considerada importante pelos entrevistados. Isso explica a tendência atual de utilização dos serviços on-line pelos clientes. Os bancos devem conduzir pesquisas para determinar tendências futuras e os desenvolvedores altamente qualificados devem ser recrutados para ajudar no desenvolvimento destes serviços (VAN TONDER et al., 2018).

Além disso, é importante que os bancos garantam que seus clientes acreditem na confiabilidade do serviço bancário eletrônico e que vale a pena recomendá-los a amigos e familiares (VAN TONDER et al., 2018). A reputação do banco, a integridade, a popularidade e acreditar nas informações do banco (v4) tiveram elevadas avaliações dos entrevistados. Como o setor bancário é baseado em relacionamentos confiáveis entre o banco e seus clientes, o conceito de confiança é importante para medir a reputação em termos de clientes (CINTAMÜR; YÜKSEL, 2018).

Tabela 1 - Variáveis do Atendimento do Setor Bancário

\begin{tabular}{clcc}
\hline \multicolumn{1}{c}{ Variável } & Média & $\begin{array}{c}\text { Desvio } \\
\text { Padrão }\end{array}$ \\
\hline v16 & Qualidade dos serviços on-line do meu banco é boa & 1,457 \\
v12 & A reputação do banco é confiável & 5,500 & 1,729 \\
v5 & O banco demonstra alta integridade no relacionamento com os clientes & 5,348 & 1,135 \\
v4 & Eu acredito nas informações fornecidas pelo banco & 5,075 & 1,598 \\
v15 & A qualidade dos serviços on-line foi importante na escolha do banco & 4,917 & 2,037 \\
v6 & Eu recomendo este banco para outros clientes & 4,879 & 1,753 \\
v7 & Eu tenho intenção de usar mais serviços do banco & 4,772 & 1,826 \\
v13 & Eu trocaria de banco caso recebesse uma proposta de preços menor & 4,715 & 2,056 \\
v2 & O banco cumpre as promessas & 4,708 & 1,581 \\
v1 & O banco demonstra empenho em atender bem os clientes & 4,689 & 1,623 \\
v9 & Trocar de banco é uma perda de tempo e muito esforço para mim & 4,626 & 2,125 \\
v14 & A localização da agência foi importante para a escolha do banco & 4,405 & 2,237 \\
v3 & A popularidade do banco é boa & 4,139 & 1,652 \\
v10 & Os preços dos serviços são caros para eu trocar de banco & 3,835 & 2,028 \\
v11 & Este banco exige pouca precaução dos clientes & 3,772 & 1,826 \\
v8 & Eu continuo cliente deste banco mesmo que os preços cobrados subam & 3,519 & 1,897 \\
\hline
\end{tabular}
Fonte: Pesquisa de Campo (2019).

Os bancos de varejo devem garantir serviços fáceis, seguros e transparentes e que isso esteja sempre disponível para o cliente. A confiança do cliente pode ser obtida garantindo que os erros relacionados à tecnologia sejam limitados e criando consciência das medidas de segurança que impedirão transações fraudulentas (VAN TONDER et al., 2018).

Os clientes recomendam os seus bancos de relacionamento e admitem interesse em continuar comprando seus produtos. Essas variáveis estão relacionadas com os estudos de Cintamür e Yüksel (2018), que explicam a avaliação boca a boca positiva do banco e a intenção de comprar produtos como importantes variáveis que fortalecem a reputação dos bancos e melhoram as decisões estratégicas de marketing.

Os bancos cumprirem as promessas e demonstrarem interesse em atender bem o cliente fortalecem a sua reputação junto aos clientes. Quando os bancos atingem um nível elevado confiança, o relacionamento com os clientes exige menos precaução e a fidelização é permanente.

Como em todo mercado competitivo, os preços cobrados são variáveis relevantes para os clientes. Quando um banco oferece produtos mais baratos para clientes com relacionamento nos bancos concorrentes, 
os clientes fidelizados são mais difíceis de serem seduzidos. Trocar de banco é custoso para o cliente, tanto em valores financeiros quanto em tempo gasto. Permanecer no mesmo banco por mais tempo é vantajoso para o cliente e isso deve ser aproveitado pelos bancos ao elaborar suas estratégias de marketing.

A localização das agências ainda é importante para os clientes, embora as visitas dos clientes nas agências bancárias tenham diminuído, devido ao uso dos canais eletrônicos. A possível explicação é que mesmo sem utilizar frequentemente as agências físicas, os clientes desejam que esta opção permaneça acessível, pois a tecnologia pode apresentar falhas ou interrupções e alguns clientes ainda possuem aversão ao uso da tecnologia para determinados serviços bancários.

\subsection{Análise fatorial dos resultados}

A análise fatorial iniciou pela verificação da adequação da amostra a técnica. A determinante da matriz de dados, com valor maior que zero, recomendava o prosseguimento dos testes de ajustamento. Os testes de Kaiser-Meyer-Olkin $(0,899)$ e de esfericidade de Bartlett $(\chi 2=1067,525$ e sig.<0,000) confirmaram a utilização da técnica satisfatoriamente, conforme Hair et al. (2009). Esses resultados possibilitaram o prosseguimento do tratamento de dados e a utilização da análise fatorial exploratória (AFE) para sumarizar as variáveis e identificar os fatores latentes.

Dessa forma, a extração dos fatores ocorreu pelo critério do Autovalor, extraído com a técnica de Componentes Principais e rotação ortogonal pelo método Varimax. Esse conjunto de procedimentos possibilitou reduzir as dezesseis variáveis originais em dez, organizadas em dois fatores denominados como: (1) reputação e confiabilidade (2) serviços on-line. Todas as variáveis apresentaram comunalidade acima de 0,500. Esses resultados mostram que pelo menos $50 \%$ da variância das variáveis foram explicadas pelos fatores.

A consistência interna dos fatores foi avaliada pelo coeficiente Alpha de Cronbach que teve o resultado de 0,916. Mensurar a consistência interna é uma etapa necessária para avaliar os fatores e o questionário. $\mathrm{O}$ intuito é saber se eles demostram capacidade de medir o que se propõem a fazê-lo. Hair et al. (2009) destacam que alfas superiores a 0,600 em uma escala de 0,000 a 1,000, são considerados satisfatórios. A Tabela 2 apresenta os resultados da análise fatorial.

Tabela 2 - Resultado da Análise Fatorial

\begin{tabular}{|c|c|c|c|c|}
\hline & Denominação do Fator & $\begin{array}{c}\text { Quantidade de } \\
\text { Variáveis }\end{array}$ & Autovalor & $\begin{array}{l}\text { Variância } \\
\text { Explicada }\end{array}$ \\
\hline Fator 1 & $\begin{array}{l}\text { Reputação, relacionamentos de confiança e } \\
\text { atendimento assertivo }\end{array}$ & 8 & 5,90 & 59,02 \\
\hline \multirow[t]{2}{*}{ Fator 2} & Qualidade e confiabilidade dos serviços on-line & 2 & 1,12 & 11,25 \\
\hline & Total & 10 & 7,02 & 70,27 \\
\hline
\end{tabular}

Fonte: Pesquisa de Campo (2019).

As variáveis v1 a v8 fazem parte do fator "Reputação, Relacionamentos de Confiança e Atendimento Assertivo". As variáveis v15 e v16 fazem parte do fator "Qualidade e Confiabilidade dos Serviços Online". A Tabela 3 apresenta os resultados da carga fatorial e comunalidades para as variáveis explicadas.

A reputação, relacionamentos de confiança e atendimento assertivos são fatores que revelam a importância da qualidade do atendimento para a satisfação e fidelização dos clientes bancários. Choudhury (2013) destaca que quando o banco comete erros evitáveis, atende negligentemente o cliente e falha nas promessas estabelecidas, há um abalo nas relações banco-cliente, resultando em insatisfação. Os bancos devem reforçar a reputação através de relacionamentos de confiança e atendimentos assertivos.

Com o crescente uso da tecnologia da informação pelos clientes, a qualidade e confiabilidade dos serviços on-line torna-se um fator importante para os bancos. Hamzah, Lee e Moghavvemi (2017) indica que a confiabilidade e segurança dos serviços bancários pela internet faz parte das dimensões positivas sobre a qualidade percebida pelos clientes dos bancos. 
Os clientes necessitam realizar suas transações bancárias em ambientes tecnológicos seguros, confiáveis, rápidos e que seja de fácil aprendizado. Os bancos devem atentar-se para essa característica e continuar os investimentos para aprimorar a tecnologia da informação disponível.

Tabela 3 - Variáveis Explicadas

\begin{tabular}{llcc}
\hline \multicolumn{1}{c}{ Variável } & $\begin{array}{c}\text { Carga } \\
\text { Fatorial }\end{array}$ & $\mathrm{h}^{2}$ \\
\hline v1 & O banco demonstra empenho em atender bem os clientes & 0,788 & 0,736 \\
v2 & O banco cumpre as promessas & 0,823 & 0,728 \\
v3 & A popularidade do banco é boa & 0,672 & 0,533 \\
v4 & Eu acredito nas informações fornecidas pelo banco & 0,778 & 0,653 \\
v5 & O banco demonstra alta integridade no relacionamento com os clientes & 0,795 & 0,698 \\
v6 & Eu recomendo este banco para outros clientes & 0,873 & 0,803 \\
v7 & Eu tenho intenção de usar mais serviços do banco & 0,850 & 0,757 \\
v8 & Eu continuo cliente deste banco mesmo que os preços cobrados subam & 0,728 & 0,535 \\
v15 A qualidade dos serviços on-line foi importante na escolha do banco & 0,884 & 0,808 \\
v16 & Qualidade dos serviços on-line do meu banco é boa & 0,837 & 0,775 \\
\hline
\end{tabular}

Fonte: Pesquisa de Campo (2019).

\section{CONCLUSÃO}

Esse tema é relevante para o estudo de satisfação e fidelização de clientes pelas empresas. Independentemente do setor de atuação das empresas, a área de marketing é sensível aos efeitos da satisfação e fidelização dos clientes. Neste trabalho, a investigação abordou a satisfação e fidelização dos clientes do setor bancário, entretanto, outros segmentos poderão replicar os resultados desta pesquisa em suas análises, ou até mesmo, aprimorar suas estratégias de marketing.

Esta investigação foi realizada para entender os motivos que levam os clientes bancários tornaremse satisfeitos e fidelizados. O mercado bancário é extremamente competitivo e conhecer maneiras de satisfazer e fidelizar os clientes é uma importante vantagem para os bancos. O cliente satisfeito e fidelizado de hoje pode não ser amanhã. A satisfação e fidelização dos clientes deve ser constante e inicia-se pela qualidade dos serviços prestados pelos bancos.

Os clientes estão cada vez mais exigentes com o uso da tecnologia da informação no setor bancário e estão adotando os serviços on-line diariamente nas suas operações, pois são mais rápidos, acessíveis e possuem maior comodidade. Os serviços on-line oferecidos pelos bancos estão substituindo as visitas presenciais dos clientes nas agências e revelando que a confiança na tecnologia da informação poderá ser um diferencial para os bancos.

Como resultado deste trabalho, os clientes bancários percebem a reputação, o relacionamento de confiança, o atendimento assertivo, a qualidade e confiabilidade dos serviços on-line como fatores importantes para a satisfação e fidelização. Esses resultados demonstram a importância de conhecer os motivos que levam os clientes a tornarem-se satisfeitos e como consequência fidelizados. A qualidade do atendimento é importante na satisfação e fidelização dos clientes do setor bancário.

A recomendação deste trabalho é que os bancos elaborem ações estratégicas para atender às necessidades dos clientes, com o objetivo de mantê-los satisfeitos por mais tempo. Resolver os problemas com rapidez e assertividade ajudam na satisfação e fidelização dos clientes. Como consequência, os clientes satisfeitos são mais fidelizados. A troca de bancos é custoso para os clientes, tanto pela perda de tempo, tanto pelos gastos financeiros decorridos. A troca de bancos é considerada uma opção para clientes insatisfeitos com os serviços prestados.

Como consequência da realização deste trabalho, é o possível haver interesse dos bancos na utilização dos resultados desta pesquisa para aprimorar a qualidade do atendimento com os clientes. Este trabalho tem duas pretensões adicionais e são elas. (1) servir de base para outras pesquisas que promovam o estudo da satisfação e fidelização de clientes no Brasil; e (2) aproximar o ambiente de mercado (profissionais e praticantes) da academia (professores e pesquisadores). 
Por fim, sugere-se novas pesquisas em outras regiões do Brasil e outros segmentos de mercado, para entender se os resultados são semelhantes ao encontrado nesta investigação, possibilitando preencher as lacunas de pesquisa existentes nesta área.

\section{REFERÊNCIAS}

ALI, Muhammad; RAZA, Syed Ali. Service quality perception and customer satisfaction in Islamic banks of Pakistan: the modified SERVQUAL model. Total Quality Management \& Business Excellence, v. 28, n. 5-6, p. 559-577, 2017.

AMEGBE, Hayford; OSAKWE, Christian Nedu. Towards achieving strong customer loyalty in the financial services industry: Ghanaian top banks' customers as a test case. International Journal of Bank Marketing, v.36, n. 5, p. 988-1007, 2018.

BAUMANN, Chris; ELLIOTT, Greg; HAMIN, Hamin. Modelling customer loyalty in financial services: a hybrid of formative and reflective constructs. International Journal of Bank Marketing, v. 29, n. 3, p. 247-267, 2011.

BEZERRA, Nathalia Dutra; MIRANDA, Julia Alves; MOREIRA, Artur Luiz Santana. ANÁLISE HIERÁRQUICA DE CRITÉRIOS NO PROCESSO DE ESCOLHA PARA ABERTURA DE CONTA UNIVERSITÁRIA. Caderno Profissional de Administração da UNIMEP, v. 6, n. 2, p. 79-101, 2016.

CASTRO, Guilherme Caldas de et al. Comportamento do consumidor e pesquisa de mercado. São Paulo: Editora FGV, 2006.

CHOUDHURY, Koushiki. Service quality and customers' purchase intentions: an empirical study of the Indian banking sector. International Journal of Bank Marketing, v. 31, n. 7, p. 529-543, 2013.

CHUMPITAZ CACERES, Ruben; PAPAROIDAMIS, Nicholas G. Service quality, relationship satisfaction, trust, commitment and business-to-business loyalty. European journal of marketing, v. 41, n. 7/8, p. 836-867, 2007.

CINTAMÜR, İsmail Gökhan; YÜKSEL, Cenk Arsun. Measuring customer based corporate reputation in banking industry: Developing and validating an alternative scale. International Journal of Bank Marketing, v. 36, n. 7, p. 1414-1436, 2018.

EAST, R. Consumer behaviour: Advances and applications in marketing. London: Prentice-Hall, 1997.

FEDERAÇÃO BRASILEIRA DOS BANCOS. Relatório anual de 2017. Disponível em:

https://portal.febraban.org.br/paginas/19/pt-br/relatorio-anual. Acesso em: 02 set. 2018.

HAIR JR, Joseph. et al. Análise multivariada de dados. 6. ed. Porto Alegre: Bookman, 2009.

HAMZAH, Zalfa Laili; LEE, Siew Peng; MOGHAVVEMI, Sedigheh. Elucidating perceived overall service quality in retail banking. International Journal of Bank Marketing, v. 35, n. 5, p. 781-804, 2017.

INSITITUTO BRASILEIRO DE GEOGRAFIA E ESTATÍSTICA. Pesquisa Nacional por Amostra de Domicílios

Contínua - PNAD Contínua. Disponível em: https://www.ibge.gov.br. Acesso em: 28 maio 2018.

LEVESQUE, Terrence; MCDOUGALL, Gordon HG. Determinants of customer satisfaction in retail banking. International journal of bank marketing, v. 14, n. 7, p. 12-20, 1996.

TAYLOR, Steven A.; BAKER, Thomas L. An assessment of the relationship between service quality and customer satisfaction in the formation of consumers' purchase intentions. Journal of retailing, v. 70, n. 2, p. 163-178, 1994 
VAN TONDER, Estelle et al. Perceived value, relationship quality and positive WOM intention in banking. International Journal of Bank Marketing, v. 36, n. 7, p. 1347-1366, 2018.

ZACHARIAS, Maria Luiza Barcelos; FIGUEIREDO, Kleber Fossati; Victor Manoel Cunha de. Determinantes da satisfação dos clientes com serviços bancários. RAE-eletrônica, v. 7, n. 2, artigo 18, jul./dez, 2008.

WU, Li-Wei. Satisfaction, inertia, and customer loyalty in the varying levels of the zone of tolerance and alternative attractiveness. Journal of Services Marketing, v. 25, n. 5, p. 310-322, 2011.

YILMAZ, Veysel; ARI, Erkan; GÜRBÜZ, Hüseyin. Investigating the relationship between service quality dimensions, customer satisfaction and loyalty in Turkish banking sector: An application of structural equation model. International Journal of Bank Marketing, v. 36, n. 3, p. 423-440, 2018. 